\title{
Serine threonine kinase receptor associated protein regulates early follicle development in the mouse ovary
}

\author{
Isam B Sharum, Sofia Granados-Aparici, Fiona C Warrander, Felicity P Tournant and \\ Mark A Fenwick \\ Academic Unit of Reproductive and Developmental Medicine, Department of Oncology and Metabolism, \\ University of Sheffield, Sheffield, UK \\ Correspondence should be addressed to M A Fenwick; Email: m.a.fenwick@shefield.ac.uk
}

\begin{abstract}
The molecular mechanisms involved in regulating the development of small, gonadotrophin-independent follicles are poorly understood; however, many studies have highlighted an essential role for TGFB ligands. Canonical TGFB signalling is dependent upon intracellular SMAD proteins that regulate transcription. STRAP has been identified in other tissues as an inhibitor of the TGFB-SMAD signalling pathway. Therefore, in this study we aimed to determine the expression and role of STRAP in the context of early follicle development. Using qPCR, Strap, Smad3 and Smad7 revealed similar expression profiles in immature ovaries from mice aged 4-16 days containing different populations of early growing follicles. STRAP and SMAD2/3 proteins co-localised in granulosa cells of small follicles using immunofluorescence. Using an established culture model, neonatal mouse ovary fragments with a high density of small non-growing follicles were used to examine the effects of Strap knockdown using siRNA and STRAP protein inhibition by immuno-neutralisation. Both interventions caused a reduction in the proportion of small, non-growing follicles and an increase in the proportion and size of growing follicles in comparison to untreated controls, suggesting inhibition of STRAP facilitates follicle activation. Recombinant STRAP protein had no effect on small, non-growing follicles, but increased the mean oocyte size of growing follicles in the neonatal ovary model and also promoted the growth of isolated preantral follicles in vitro. Overall findings indicate STRAP is expressed in the mouse ovary and is capable of regulating development of small follicles in a stage-dependent manner.

Reproduction (2017) $153221-231$
\end{abstract}

\section{Introduction}

The ovarian reserve consists of a limited number of small follicles each made up of an immature oocyte surrounded by a single layer of granulosa cells (GCs) (Hirshfield 1991, Gougeon 1996). Throughout life, some of these follicles undergo developmental changes that precipitate an increased rate of oocyte growth and GC proliferation (Hirshfield 1991, Da Silva-Buttkus et al. 2008, Adhikari \& Liu 2009). The molecular mechanisms that regulate this co-ordinated event are still unresolved; however, a number of ovarian-expressed growth factors and signalling molecules have been implicated, particularly in relation to the $\mathrm{PI} 3$ kinase and mTOR pathways (Adhikari \& Liu 2009). The transforming growth factor beta (TGFB) pathway is also important in this context, since various mutations in specific ligands and receptors have revealed striking effects on early follicle development and consequentially, fertility (Dong et al. 1996, Galloway et al. 2000, Edson et al. 2009). However, very little is known about the molecular regulation of TGFB signalling in small follicles, and how other factors interacting with this pathway may influence early growth or arrest.

TGFB signalling involves ligand binding to specific Type-1 and Type-2 cell surface receptors where the kinase activity is propagated by phosphorylation of receptorregulated SMAD (R-SMAD) proteins (Shi \& Massague 2003). Activated R-SMADs then form a complex with SMAD4, which facilitates nuclear import and dwell time, leading to DNA binding and regulation of target genes (Wakefield \& Hill 2013). Activins, TGFB1-3 and growth differentiation factor 9 (GDF9) tend to signal mainly via SMAD2/3, while anti-Müllerian hormone $(\mathrm{AMH})$ and bone morphogenetic proteins (BMPs) utilise SMAD1/5/9 (Wakefield \& Hill 2013). Transgenic mouse models harbouring GC-specific (conditional) mutations in each of these R-SMADs have revealed fundamental roles for TGFB signalling in growing follicles (Li et al. 2008, Pangas et al. 2008, Middlebrook et al. 2009); however, the distinct role of this pathway in small, single-layered (non-growing) follicles is still unclear. Recent studies have also highlighted distinct, differential expression 
of R-SMADs in granulosa cells, with SMAD1/5/8 localised in multi-layered, growing preantral follicles and SMAD2/3 predominantly localised in small, singlelayered follicles (Xu et al. 2002, Fenwick et al. 2013). This indicates that SMAD2/3 may be an important regulator of the very early stages of follicle development.

The TGFB pathway is highly conserved across a range of species, and within species is a pivotal regulator of numerous developmental processes that influence cell phenotype (Massague 2012, Wakefield \& Hill 2013). Fine control of the TGFB pathway is achieved in part by the different interacting proteins (Wakefield \& Hill 2013). One example is SMAD7, which is induced by R-SMADs and acts to negatively regulate TGFB signalling by binding and promoting R-SMAD or receptor degradation (Nakao et al. 1997, Itoh \& ten Dijke 2007, Yan et al. 2016). Although the role of SMAD7 during early follicle development has not been determined, recent studies have shown that SMAD7 regulates TGFB signals and apoptosis of GCs from growing follicles (Quezada et al. 2012, Shimizu et al. 2012, Gao et al. 2013). In other cell types, the activity of SMAD7, and consequently SMAD2/3, is further regulated by serine threonine kinase receptor associated protein (STRAP) (Datta et al. 1998). STRAP acts by stabilising a complex between TGFBR1 and SMAD7, thereby preventing SMAD2 and SMAD3 from access to the Type 1 receptor (Datta et al. 2000). STRAP may therefore represent an indirect, negative regulator of TGFB signalling in the ovary.

In this study we aimed to determine if STRAP plays a role in small follicles. We show that transcript levels of Strap, Smad3 and Smad7 exhibit similar expression profiles in immature mouse ovaries enriched with different proportions of non-growing and early growing follicles. Using an in vitro model to monitor follicle activation, we also show that STRAP modulation using different interventions leads to changes in the proportions of non-growing and growing follicles, consistent with a role for the TGFB pathway as an important regulator of early follicle development.

\section{Materials and methods}

\section{Animals and tissues}

All tissues used in this study were obtained from wildtype C57Bl6 mice housed under standard conditions in compliance with the Animals and Scientific Procedures Act, 1986, and also in accordance with approval from the University of Sheffield Training and Competency Officer. Ovaries were dissected from female mice at precisely $4,8,13$ and 16 days of age $(\mathrm{d} 4, \mathrm{~d} 8, \mathrm{~d} 13, \mathrm{~d} 16)$ and finely dissected free of adhering tissue in isolation media consisting of Liebovtiz L-15 (Life Technologies, ThermoFisher) with 1\% $(\mathrm{w} / \mathrm{v})$ bovine serum albumin (BSA; Sigma-Aldrich). Ovaries were used immediately for culture or were rinsed in PBS and frozen in liquid nitrogen for later RNA analysis or were fixed in $10 \%$ neutral buffered formalin (NBF; Sigma) for paraffin embedding, sectioning $(5 \mu \mathrm{m})$ and staining.

\section{RNA extraction, cDNA and quantitative PCR}

Total RNA was extracted from $\mathrm{d} 4, \mathrm{~d} 8$ and $\mathrm{d} 16$ ovaries using RNeasy microcolumns, which includes a DNase digestion step (Qiagen). The quality of all RNA samples was assessed with an Agilent 2100 Bioanalyser (Agilent Technologies) and only those with an integrity value of 9-10 were included. An equivalent amount of RNA from all samples (50 ng) was converted to cDNA using random hexamer primers and SuperScript III reverse transcriptase in accordance with the manufacturer's guidelines (Invitrogen, ThermoFisher). For quantitative PCR assays, a reaction mixture consisting of nuclease-free $\mathrm{H}_{2} \mathrm{O}$, Kapa SYBR Green and ROX dye (Kapa Biosystems Ltd., London, UK) was combined with $500 \mathrm{nM}$ gene-specific primers (Table 1) and added to a 384-well plate. All primers were initially confirmed for suitability for qPCR by the presence of a single band at the

Table 1 Primer sequences used for PCR assays in mouse ovaries.

\begin{tabular}{|c|c|c|c|}
\hline Gene symbol & Primer sequence $\left(5^{\prime} \rightarrow 3^{\prime}\right)$ & GenBank accession & Product size (bp) \\
\hline Smad1 & $\begin{array}{l}\text { Fwd: ACСТGСТТАССТGССТССТ } \\
\text { Rev: GCCTGAАCATCТССТСТGCT }\end{array}$ & NM_008539.3 & 114 \\
\hline Smad2 & $\begin{array}{l}\text { Fwd: CGTCCATCTTGCCATTCAC } \\
\text { Rev: GTCCATTCTGCTCTCCACCA }\end{array}$ & NM_001252481.1 & 102 \\
\hline Smad3 & $\begin{array}{l}\text { Fwd: GTCAAAGAACACCGATTCCA } \\
\text { Rev: TCAAGCCACCAGAACAGAAG }\end{array}$ & NM_016769.4 & 154 \\
\hline Smad4 & $\begin{array}{l}\text { Fwd: CGGCGATTGTGCATTCTCAG } \\
\text { Rev: CCTGGAAATGGTTAGGGCGT }\end{array}$ & NM_008540.2 & 209 \\
\hline Smad5 & $\begin{array}{l}\text { Fwd: CCTTGCTCATCTCCCTGTCT } \\
\text { Rev: CCGTGAATCTCCTTTCTGTG }\end{array}$ & NM_001164041.1 & 173 \\
\hline Smad6 & $\begin{array}{l}\text { Fwd: TGCAACCCCTACCACTTCA } \\
\text { Rev: GCTGGCATCTGAGAATTCA }\end{array}$ & NM_008542.3 & 180 \\
\hline Smad7 & $\begin{array}{l}\text { Fwd: AGTCAAGAGGCTGTGTTGCTGT } \\
\text { Rev: CATTGGGTATCTGGAGTAAGGA }\end{array}$ & NM_001042660.1 & 130 \\
\hline Smad9 & $\begin{array}{l}\text { Fwd: GTCTGACCTTGCAGATGGCT } \\
\text { Rev: TAGGTGCCAGGCTGAGAGAT }\end{array}$ & NM_019483.5 & 235 \\
\hline Strap & $\begin{array}{l}\text { Fwd: GGCTACTTTCTGATCAGCGC } \\
\text { Rev: CTGAGACCGCATCCCATACT }\end{array}$ & NM_011499.3 & 187 \\
\hline
\end{tabular}


appropriate size by gel electrophoresis. For each gene, an equal volume $(1 \mu \mathrm{L})$ of $\mathrm{cDNA}$ or $\mathrm{H}_{2} \mathrm{O}$ (control) was added to each reaction in duplicate. An initial activation step at $95^{\circ} \mathrm{C}(3 \mathrm{~min})$ was followed by cycling $(40 \times)$ at $95^{\circ} \mathrm{C}(3 \mathrm{~s})$, $58^{\circ} \mathrm{C}(20 \mathrm{~s})$ and $72^{\circ} \mathrm{C}(10 \mathrm{~s})$ using an Applied Biosystems $7900 \mathrm{HT}$ Fast instrument (Applied Biosystems). Fluorescence was recorded at each cycle and also during a final DNA product melting protocol to ensure consistent and specific amplification. Final CT values were normalised against mouse Atp5b (PrimerDesign, Southampton, UK), which was stably expressed across all samples and used previously in similar experiments (Fenwick et al. 2011). Fold changes relative to $\mathrm{d} 4$ ovaries were calculated using $2^{-\Delta \Delta C T}$ (Livak \& Schmittgen 2001).

\section{Immunohistochemistry}

Approximate midsections of $\mathrm{d} 4, \mathrm{~d} 8$ and $\mathrm{d} 16$ ovaries were dewaxed in Histochoice solvent (Sigma) and re-hydrated in changes of ethanol of decreasing concentrations. Slides were immersed in $0.01 \mathrm{M}$ citrate buffer $(\mathrm{pH} \mathrm{6.0)}$ ) and microwaved for $4 \times 5 \mathrm{~min}$ to retrieve antigens before washing in phosphate buffered saline (PBS; pH 7.4). Non-specific binding was blocked with CAS-Block (ThermoFisher) for $20 \mathrm{~min}$ before applying a mixture of rabbit anti-SMAD2/3 (1:400; \#5678; Cell Signalling Technology) and mouse anti-STRAP $(0.3 \mu \mathrm{g} / \mathrm{mL}$; sc-136083; Santa Cruz Biotechnology) diluted in CAS-Block overnight at $4{ }^{\circ} \mathrm{C}$. Primary antibodies were replaced on some sections with equivalent concentrations of non-immune mouse IgG (Vector Laboratories, Bakewell, UK) or rabbit IgG (Vector) to determine non-specific binding. After washes in PBS, all sections were incubated at room temperature for $45 \mathrm{~min}$ in a mixture of Alexa555 anti-mouse IgG (1:400; Invitrogen) and Alexa488 anti-rabbit IgG (1:400; Invitrogen) diluted in PBS. Sections were washed in PBS and mounted in ProLong Gold antifade reagent with DAPI (Invitrogen) and imaged using a Leica inverted SP5 confocal laser scanning microscope (Leica Microsystems). Images presented in this study were taken from sections stained in the same run, using the same laser and gain settings.

\section{Ovary fragment culture}

Ovaries from $\mathrm{d} 4$ mice were finely cut into $6-8$ equivalent-sized pieces in drops of isolation media and placed into a single well of a 24-well cell culture plate (Sigma). Each well contained $1 \mathrm{~mL}$ of culture medium consisting of MEM- $\alpha$ (ThermoFisher) supplemented with $10 \%(\mathrm{v} / \mathrm{v})$ foetal bovine serum (FBS; ThermoFisher), streptomycin sulphate $100 \mu \mathrm{g} / \mathrm{mL}$ (Sigma) and penicillin $75 \mu \mathrm{g} / \mathrm{mL}$ (Sigma). To assess the effects of exogenous STRAP protein on early follicle development, ovary fragments were treated with 0 (diluent only; control), 100 or $200 \mathrm{ng} / \mathrm{mL}$ Human Unrip full-length recombinant protein (designated rhSTRAP; ab132509; Abcam). For immuno-neutralisation experiments, media was supplemented with either 1 or $10 \mu \mathrm{g} /$ $\mathrm{mL}$ rabbit anti-STRAP (AB1) IgG (AV48038; Sigma). Control wells were instead supplemented with 0,1 or $10 \mu \mathrm{g} / \mathrm{mL}$ of nonimmune rabbit IgG (Vector). For the siRNA experiments, ovary fragments were initially maintained in culture media alone for three days before supplementation with either $1 \mu \mathrm{M}$ Accell mouse STRAP siRNA (E-045977; Dharmacon, ThermoFisher), or $1 \mu \mathrm{M}$ Accell non-targeting siRNA (D-001910-10; Dharmacon). Both siRNA contain a mixture of four oligonucleotides provided as a single reagent. Additional control wells without siRNA were also included. One well from each group was collected at the termination of culture for analysis of STRAP mRNA expression by qPCR according to the procedures described above. All cultures were carried out three times ( $n=3$ ovaries/group/experiment). After three days at $37^{\circ} \mathrm{C}$ and $5 \% \mathrm{CO}_{2}$, ovary fragments would adhere and spread on the base of the well. This permits visualisation of oocytes with a standard inverted light microscope (Olympus CKX41 with a Nikon camera DS-Fi1). Using this approach, we were able to capture images and measure oocyte diameters using ImageJ (http://imagej.nih.gov/ij/) to monitor growth at specified time points during culture. Only oocytes with a clearly identifiable boundary were counted and measured. At the end of culture, some ovary fragments were briefly fixed in 10\% NBF (Sigma), washed in PBS, treated with $0.25 \%(\mathrm{v} / \mathrm{v})$ triton X-100 (Sigma) for $15 \mathrm{~min}$, and blocked in CAS-Block (ThermoFisher) before applying a solution of rabbit anti-Ddx4 $(5 \mu \mathrm{g} / \mathrm{mL}$; ab13840; Abcam) and mouse anti-Amh (1:400; MCA2246; AbD Serotec, Oxford, UK) followed by overnight incubation at $4{ }^{\circ} \mathrm{C}$. Tissues were washed in PBS before applying secondary antibodies as above. After further washing in PBS, tissues were counterstained in $10 \mu \mathrm{g} / \mathrm{mL}$ DAPI (Sigma) for $10 \mathrm{~min}$ before being replaced by PBS. Images were recorded using an Olympus IX73 inverted microscope.

\section{Classification of oocytes}

Oocytes from ovary fragment cultures were classified as non-growing, transitional or growing using morphological parameters obtained from haematoxylin and eosin stained sections. One section was analysed from each ovary from the following ages: $\mathrm{d} 4(n=5), \mathrm{d} 8(n=8), \mathrm{d} 13(n=5)$ and $\mathrm{d} 16(n=7)$. Digital images of each section were recorded with a light microscope and were imported to ImageJ. Oocyte diameters were measured in all follicles that had a clearly identifiable oocyte nucleus. Follicles were classified as non-growing (primordial) if it had a single layer of relatively flat granulosa cells. Transitional follicles had of a mixture of flat and enlarged/cuboidal granulosa cells in a single layer. Follicles were considered to be growing if they contained at least one complete layer of enlarged granulosa cells and a visually larger oocyte. After plotting these distributions (Supplementary Fig. 1, see section on supplementary data given at the end of this article), we considered any oocyte smaller than one standard deviation from the mean of the transitional category to be defined as non-growing $(<18.3 \mu \mathrm{m})$, and conversely any oocyte larger than one standard deviation from the mean of the transitional category to be defined as growing $(>25.7 \mu \mathrm{m})$. Any oocyte diameter between these boundaries was defined as transitional (18.3-25.7 $\mu \mathrm{m})$. Across all ages, a total of 992 nongrowing, 292 transitional and 331 growing preantral follicles were measured. 


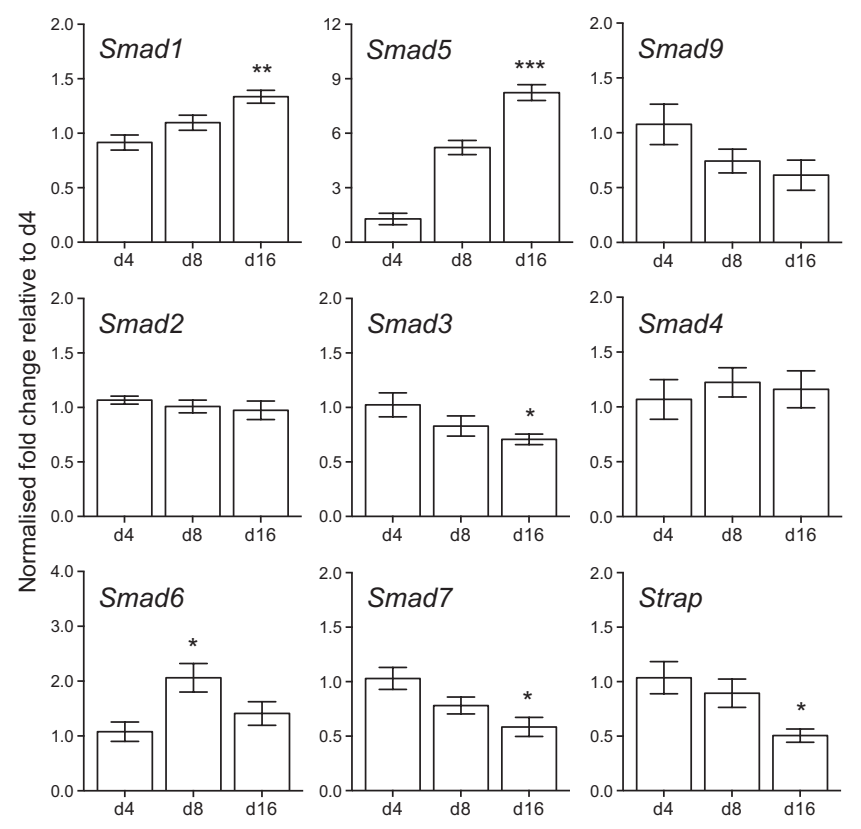

Figure 1 Relative mRNA expression of Smads and Strap in juvenile mouse ovaries. Transcripts were amplified from cDNA derived from whole mouse ovaries by qPCR and normalised with endogenous Atp $5 b$ as described in 'Materials and methods' section. Fold changes (mean \pm S.E.M.) in $\mathrm{d} 8$ and $\mathrm{d} 16$ ovaries are shown relative to $\mathrm{d} 4$. Smad1-3, 5, 7, $n=6$ ovaries each age; Smad4, Smad6, Smad9 and Strap, $n=5$ ovaries each age; $* P<0.05$ vs d4, ${ }^{* *} P<0.01$ vs d4, ***P $P<0.001$ vs d4, Dunn's multiple comparisons test.

\section{Preantral follicle culture}

Preantral follicles from d16 ovaries $(n=7)$ were mechanically dissected in drops of isolation media using acupuncture needles as previously described (Fenwick et al. 2013). Follicles of similar size and appearance were transferred into 96-well plates with each well containing $100 \mu \mathrm{L}$ MEM- $\alpha$ (ThermoFisher) supplemented with $0.1 \%$ (w/v) BSA (Sigma), $75 \mu \mathrm{g} / \mathrm{mL}$ penicillin (Sigma), $100 \mu \mathrm{g} / \mathrm{mL}$ streptomycin sulphate (Sigma) and insulin-transferrin-sodium selenite (ITS; Sigma; $5 \mu \mathrm{g} / \mathrm{mL}, 5 \mu \mathrm{g} / \mathrm{mL}, 5 \mathrm{ng} / \mathrm{mL}$, respectively). A single follicle was placed into each well; 8 wells contained media with $200 \mathrm{ng} / \mathrm{mL}$ rhSTRAP (Abcam), while 8 contained media with diluent only (control). Each plate contained follicles from a single ovary, which were maintained for $72 \mathrm{~h}$ at $37^{\circ} \mathrm{C}$ and $5 \% \mathrm{CO}_{2}$. Follicles were imaged daily using an Olympus CKX41 inverted microscope and diameters were determined from perpendicular measurements taken from the basement membrane of the follicle using ImageJ. Any follicles containing an oocyte that showed signs of degeneration or extrusion were excluded from the analysis.

\section{Statistical analyses}

For qPCR data, comparisons between $\mathrm{d} 4$, d8 and d16 samples ( $n=5$ or 6 ovaries per age group as stated) were analysed by a Kruskal-Wallis test followed by a post hoc Dunn's multiple comparisons test. For cultured ovarian fragments, proportions were grouped by treatment and stage and analysed using a two-way ANOVA ( $n=3$ cultures per treatment). Post-hoc Bonferroni multiple comparisons tests were used to identify specific differences (effect of treatment) within each stage (non-growing, transitional, growing). For each experiment, growing oocytes from all three cultures were considered together (number as stated in figure legends) and analysed using a Kruskal-Wallis and Dunn's multiple comparisons test to determine effect of treatment at each time point. Preantral follicle growth was analysed by a two-way repeatedmeasures ANOVA ( $n=7$ ovaries), with a Bonferroni's multiple comparisons test to determine effects at each time point. All analyses were performed using Prism (v6.0d; GraphPad) with differences considered significant if $P<0.05$.
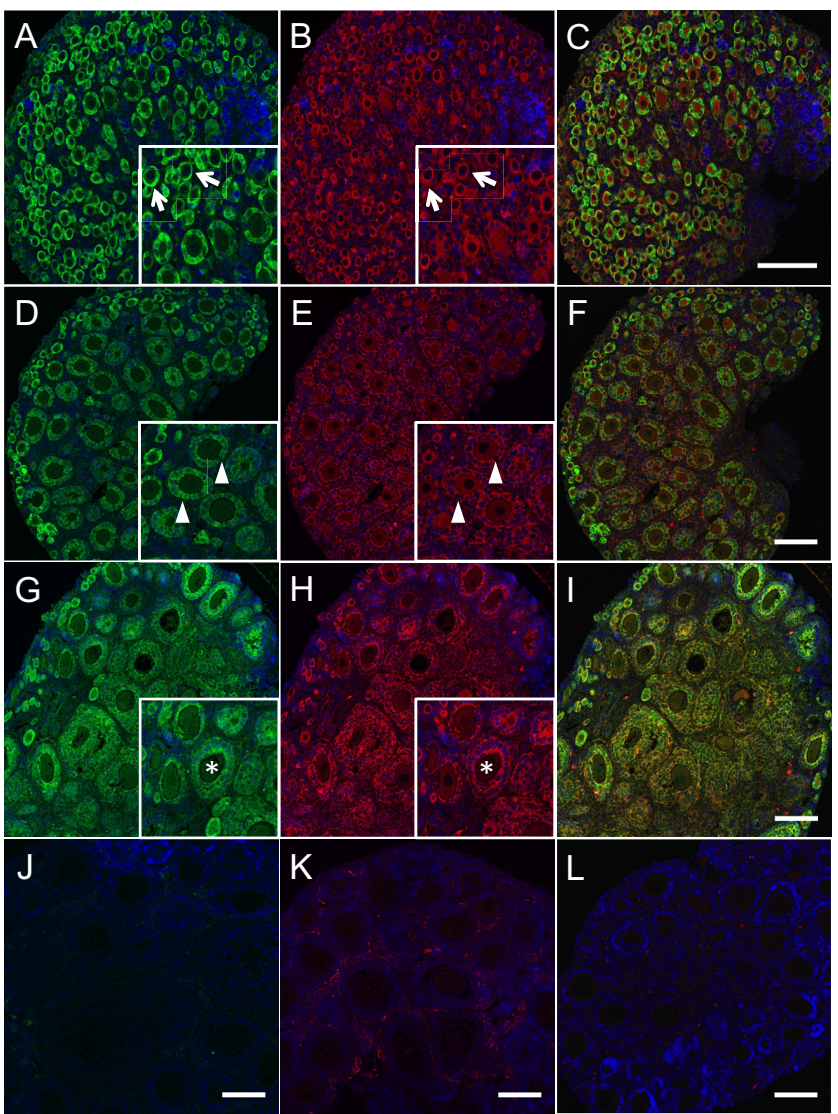

Figure 2 Co-localisation of SMAD2/3 and STRAP in juvenile mouse ovaries highlighting relationship with these proteins and early follicle development. SMAD2/3 is labelled in green (A, D, G) and STRAP is labelled in red $(B, E, H)$. Merged images $(C, F, I)$ represent ovaries from mice at $\mathrm{d} 4$ ( $\mathrm{A}, \mathrm{B}$ and $\mathrm{C}), \mathrm{d} 8(\mathrm{D}, \mathrm{E}$ and $\mathrm{F})$ and $\mathrm{d} 16(\mathrm{G}, \mathrm{H}$ and $\mathrm{I})$. Arrows, arrowheads and asterisks indicate primordial, primary and multi-layered preantral follicles, respectively. Control sections from d16 mice were incubated with mouse $\operatorname{lgG}(\mathrm{J})$, rabbit $\operatorname{lgG}(\mathrm{K})$ or dilution buffer $(\mathrm{L})$ in place of the primary antibodies. All sections were counterstained with DAPI (blue). Scale $=100 \mu \mathrm{m}$. 

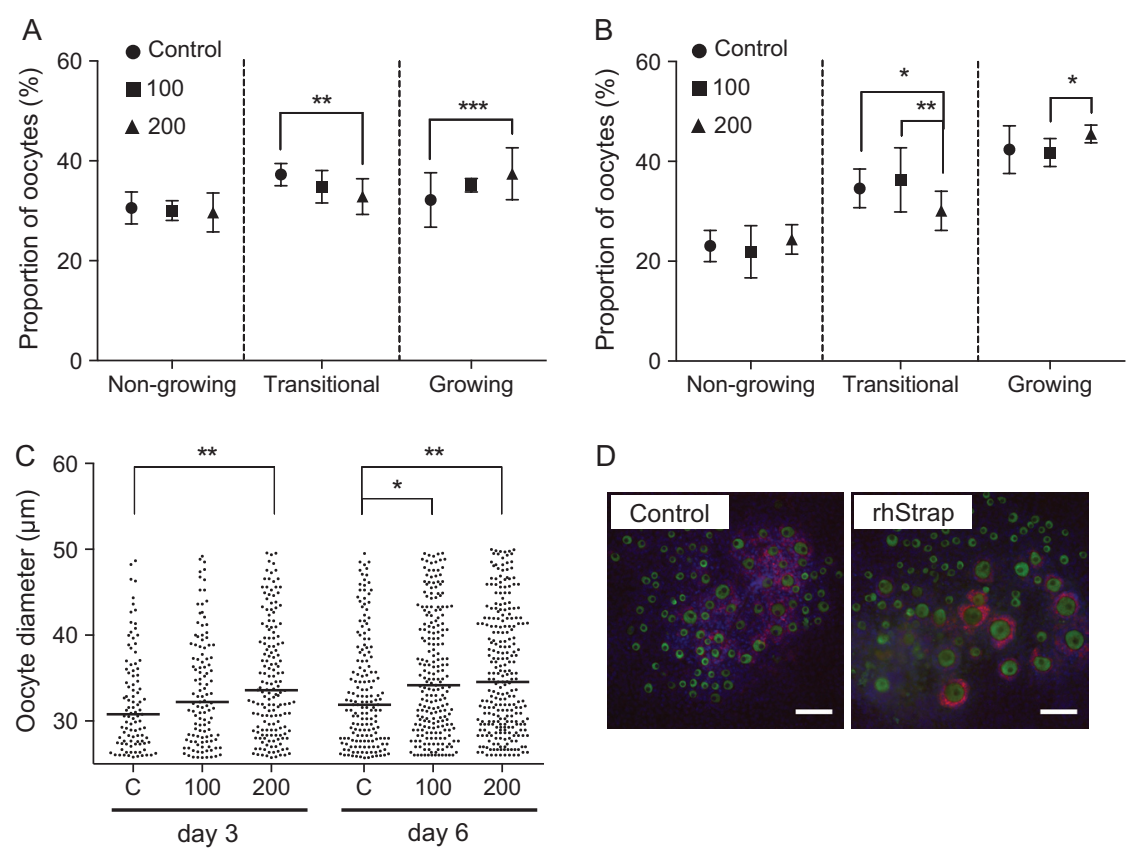

D

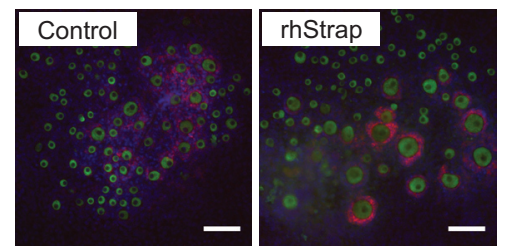

Figure 3 Effect of STRAP supplementation on small follicle growth in vitro. Ovaries from d4 mice were cut into small fragments and maintained under standard culture conditions (Control) or supplemented with $100 \mathrm{ng} / \mathrm{mL}$ (100) or $200 \mathrm{ng} / \mathrm{mL}$ (200) recombinant human STRAP (rhSTRAP). Oocytes were classified as non-growing, transitional or growing and proportions in each category are shown at day 3 (A) and day 6 of culture (B). Mean $\pm 95 \% \mathrm{Cl}$; $n=3$ cultures; $* P<0.05, * * P<0.01$,

Bonferroni's multiple comparisons test. At day 3 and 6 of culture, the median diameters (horizontal bars) of growing oocytes $(>25.7 \mu \mathrm{m})$ in each treatment group are plotted (C) ${ }^{*} P<0.05,{ }^{*} P<0.01$, Dunn's multiple comparisons test (Day $3 n=101$,

117, 164 and Day $6 n=169,221,263$ oocytes for C, 100 and 200 groups, respectively). At day 6 some wells were co-stained with $\mathrm{Ddx} 4$ (green) to label oocytes and Amh (red) to label granulosa cells of growing follicles (D). Cell nuclei were counterstained with DAPI (blue). Scale bar $=50 \mu \mathrm{m}$.

\section{Results}

\section{Expression of Strap and Smads during early follicle development}

Ovaries from 4, 8 and 16-day-old mice (d4, d8, d16) enriched with increasing proportions of developing preantral follicles were used to initially determine relative levels of mRNA of the BMP signalling SMADs: Smad1, Smad5 and Smad9 (also known as SMAD8), the TGFB signalling SMADs: Smad2 and Smad3, the Co-SMAD: Smad4, the inhibitory SMADs: Smad6 and Smad7, and Strap (Fig. 1). Transcript levels of Smad1 and Smad5 were significantly higher in $\mathrm{d} 16$ ovaries relative to $\mathrm{d} 4(P<0.01$ and $P<0.001$, respectively), while Smad9, Smad2 and Smad4 did not vary between age groups. Conversely, Smad3, Smad7 and Strap were significantly lower in $\mathrm{d} 16$ ovaries relative to $\mathrm{d} 4(P<0.05$ each). The level of Smad6 mRNA was increased in d8 ovaries relative to $\mathrm{d} 4$ only $(P<0.05)$.

To further evaluate the relationship between STRAP and the TGFB receptor regulated SMADs during early follicle development; proteins were immunolocalised in sections of $\mathrm{d} 4, \mathrm{~d} 8$ and $\mathrm{d} 16$ ovaries (Fig. 2). In d4 ovaries densely populated with primordial follicles, SMAD2/3 staining was evident in the flattened granulosa cells of single-layered follicles, being more intense in cells of primordial and transitional than early growing (primary staged) follicles. STRAP was also detectable in granulosa cells of small, single-layered follicles and was strong in primordial oocytes. In d8 ovaries, SMAD2/3 and STRAP were both detectable in granulosa cells of primary follicles and those that had begun to develop a second layer. In d16 ovaries, SMAD2/3 and STRAP remained co-localised in granulosa cells of multi-layered preantral follicles, although the intensity of SMAD2/3 staining was weaker in comparison to smaller follicles. STRAP was also detectable in extra-follicular stromal cells, although some of this could be accounted for by nonspecific binding of rabbit lgG (Fig. 2).

\section{Effect of Strap supplementation on early follicle development}

To reconcile the expression of intracellular TGFB pathway components in small follicles, we used a culture model to assess the effect of exogenous STRAP on early growth. Ovaries from d4 mice were initially dissected into fragments and maintained in vitro for 3 days to allow them to adhere and spread across the base of the well. This permits visualisation of the oocytes by light microscopy, which can be used as an indicator of follicle growth. After supplementation with 0,100 or $200 \mathrm{ng} / \mathrm{mL}$ recombinant human (rh) STRAP protein, oocyte diameters were measured 4 and 7 days later (Fig. 3). At day 4 , the proportion of oocytes classified as non-growing was similar across the three groups. The proportion of oocytes classified as transitional was slightly reduced in ovary fragments exposed to $200 \mathrm{ng} / \mathrm{mL}$ rhSTRAP vs control $(P<0.01)$. Conversely, the proportion of oocytes classified as growing was slightly elevated in ovary fragments exposed to $200 \mathrm{ng} / \mathrm{mL}$ rhSTRAP vs control $(P<0.001)$ (Fig. 3A). Similar trends were evident after 7 days of treatment: the proportion of non-growing oocytes was equivalent, whereas a reduction in the proportion of transitional oocytes was evident for ovary fragments exposed to $200 \mathrm{ng} / \mathrm{mL}$ rhSTRAP relative to both 0 and $100 \mathrm{ng} / \mathrm{mL}$ groups $(P<0.05$ and 0.01 , respectively). 

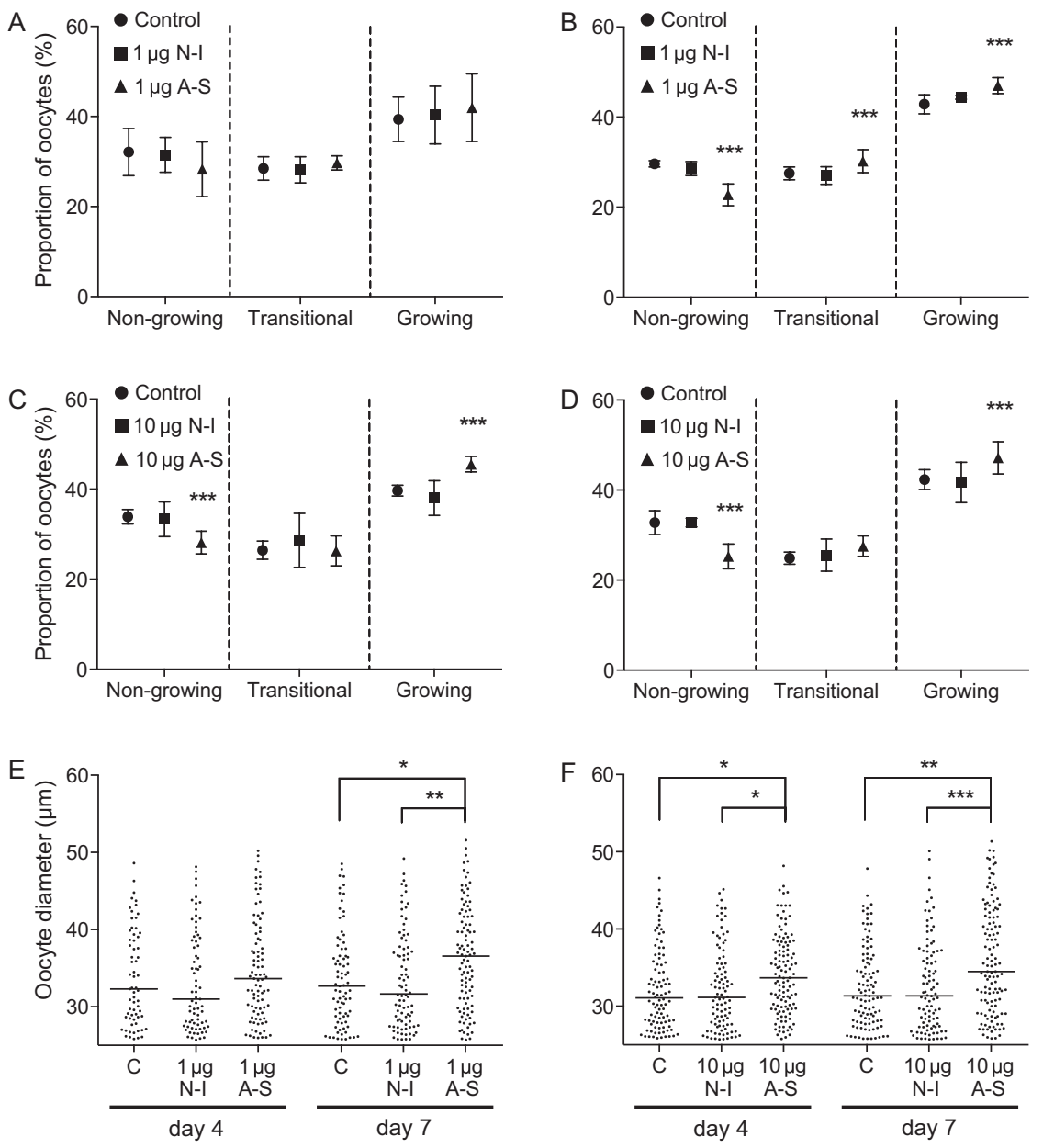

Figure 4 Effect of STRAP immunoneutralisation on small follicle growth in vitro. Ovaries from d4 mice were cut into small fragments and maintained under standard culture conditions (Control) or supplemented with non-immune $\lg \mathrm{G}(\mathrm{N}-\mathrm{I})$ or anti-STRAP IgG (A-S). Oocytes were classified as non-growing, transitional or growing and proportions in each category are shown at day 4 (A) and day 7 (B) of culture with $1 \mu \mathrm{g} / \mathrm{mL}$ supplementation and day 4 (C) and day 7 (D) of culture with $10 \mu \mathrm{g} / \mathrm{mL}$ supplementation. Mean $\pm 95 \%$ $\mathrm{Cl} ; n=3$ cultures; ${ }^{* * *} P<0.001$ vs Control and $\mathrm{N}$-I groups, Bonferroni's multiple comparisons test. At day 4 and 7 of culture, the median diameters (horizontal bars) of growing oocytes $(>25.7 \mu \mathrm{m})$ in the presence of $1 \mu \mathrm{g} / \mathrm{mL}$ (Day $4 n=65,73,89$ and Day $7 n=81,86,101$ oocytes for C, $1 \mu \mathrm{g} \mathrm{N}-\mathrm{I}$ and $1 \mu \mathrm{g}$ A-S groups, respectively) (E) and $10 \mu \mathrm{g} / \mathrm{mL}$ (F) IgG are plotted (Day $4 n=96,97,117$ and Day $7 n=102$, 98, 123 oocytes for C, $10 \mu \mathrm{g} \mathrm{N}$ - I and $10 \mu \mathrm{g}$ A-S groups, respectively). ${ }^{*} P<0.05$, ${ }^{* *} P<0.01,{ }^{* * *} P<0.001$, Dunn's multiple comparisons test.
The proportion of oocytes classified as growing was higher in ovary fragments exposed to $200 \mathrm{ng} / \mathrm{mL}$ vs $100 \mathrm{ng} / \mathrm{mL}$ rhSTRAP $(P<0.05)$ (Fig. 3B).

When only growing oocytes were considered (i.e. $>25.7 \mu \mathrm{m}$ ), the median diameter was greater in wells exposed to $200 \mathrm{ng} / \mathrm{mL}$ rhSTRAP at both 4 and 7 days $(P<0.01$ vs $0 \mathrm{ng} / \mathrm{mL})$. The median diameter of growing oocytes was also increased in fragments exposed to $100 \mathrm{ng} / \mathrm{mL}$ vs $0 \mathrm{ng} / \mathrm{mL}(P<0.05)$ at 7 days (Fig. 3C).

To determine whether an increase in oocyte diameter could be associated with markers of follicle development, some wells were stained with antibodies to clearly delineate oocytes (Ddx4) and to identify granulosa cells from growing preantral follicles (Amh) (Fig. 3D). Large Ddx4-positive oocytes were mostly surrounded by Amh-positive cells, indicating that the culture system was able to support primordial follicle activation and early preantral development. Although not quantified, Amh staining appeared to be more prevalent in the $200 \mathrm{ng} / \mathrm{mL}$ rhSTRAP treated in comparison to controls.

\section{Effect of Strap inhibition on early follicle development}

The same ovary fragment model was then used to assess the effects of STRAP protein neutralisation on oocyte growth (Fig. 4). Fragments were exposed to rabbit anti-STRAP IgG (A-S) or non-immune rabbit IgG (N-I) or no $\lg G$ (Control) for 7 days. For those treated with $1 \mu \mathrm{g} / \mathrm{mL} \mathrm{A}-\mathrm{S}$, there was no effect on the proportion of oocytes classified as non-growing, transitional or growing after 4 days (Fig. 4A). However, after 7 days, there was a significant reduction in the proportion of non-growing oocytes with a corresponding increase in the proportion of transitional and growing oocytes when compared with $\mathrm{N}-\mathrm{I}$ or Control $(P<0.001$ each) (Fig. 4B).

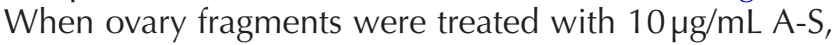
a reduction in the proportion of non-growing follicles was evident at 4 days, with a corresponding increase in the proportion of growing oocytes $(P<0.001$ vs $\mathrm{N}-\mathrm{I}$ or Control) (Fig. 4C). The same trend was also found at 7 days (Fig. 4D).

When only growing oocytes were considered, there was no detectable difference in the median diameter of 


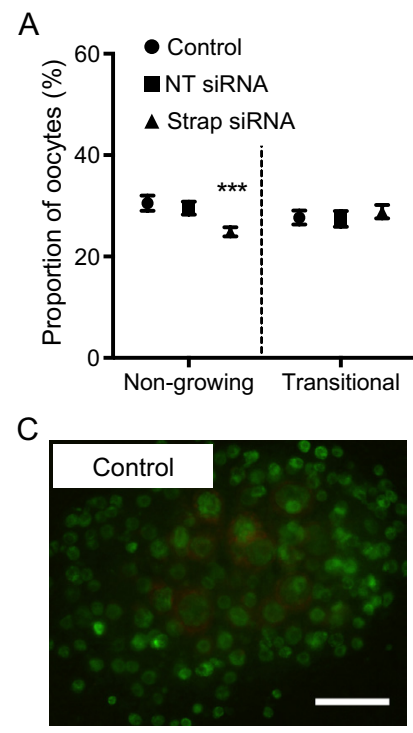

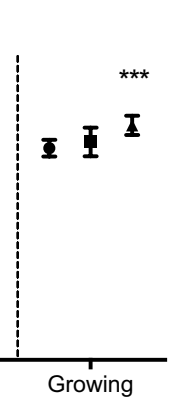
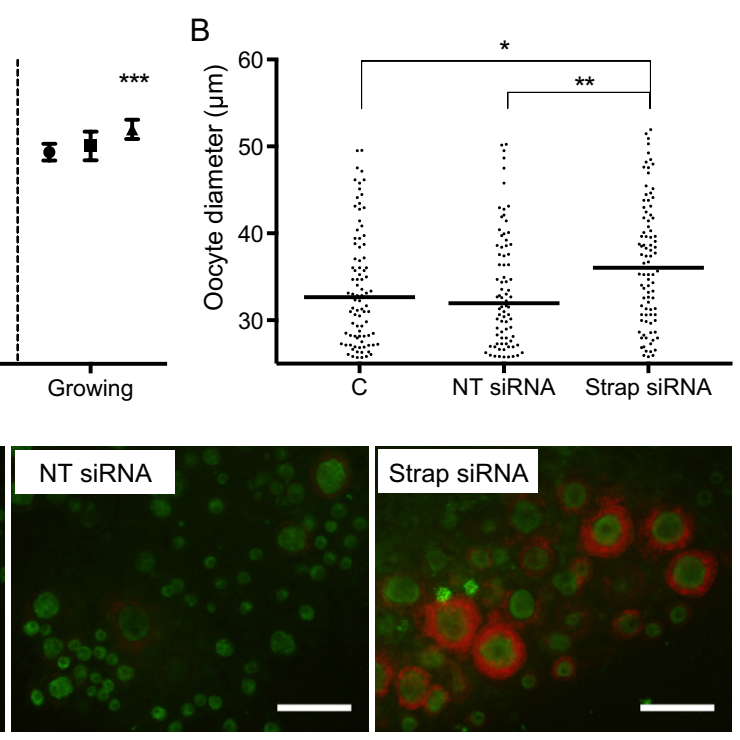

Figure 5 Effect of Strap mRNA knockdown on small follicle growth in vitro. Ovaries from d4 mice were cut into small fragments and maintained under standard culture conditions (Control) or supplemented with non-targeting siRNA (NT siRNA) or siRNA complementary to Strap mRNA (STRAP siRNA). Oocytes were classified as non-growing, transitional or growing and proportions in each category are shown for each treatment after 4 days ( 7 days of culture) (A). Mean $\pm 95 \% \mathrm{Cl} ; n=3$ cultures; $* * * P<0.001$ vs Control and NT siRNA groups, Bonferroni's multiple comparisons test. At day 7 of culture, the median diameters (horizontal bars) of growing oocytes $(>25.7 \mu \mathrm{m})$ for the different groups are plotted (B). ${ }^{*} P<0.05,{ }^{* *} P<0.01$, Dunn's multiple comparisons test ( $n=89,80,93$ oocytes for C, NT siRNA and STRAP siRNA groups, respectively). At day 7 some wells were co-stained with Ddx4 (green) to label oocytes and Amh (red) to label granulosa cells of growing follicles (C). Scale $=100 \mu \mathrm{m}$. oocytes treated with $1 \mu \mathrm{g} / \mathrm{mL}$ A-S after 4 days; however, after 7 days the median diameter was increased relative to Control $(P<0.05)$ and $\mathrm{N}-\mathrm{I}(P<0.01)$ (Fig. 4E). By comparison, the median diameter of growing oocytes was increased at 4 days when exposed to a higher concentration $(10 \mu \mathrm{g} / \mathrm{mL})$ of A-S relative to Control $(P<0.05)$ or $\mathrm{N}-\mathrm{I} \quad(P<0.05)$. This increase was also evident at 7 days $(P<0.01$ vs Control or $P<0.001$ vs $\mathrm{N}-\mathrm{I}$ ) (Fig. 4F).

In addition to protein inhibition, we then evaluated the effect of Strap mRNA inhibition using small interfering RNA (siRNA) in the same culture model (Fig. 5). Ovarian fragments were exposed to $1 \mu \mathrm{M}$ oligonucleotides targeting Strap mRNA, or $1 \mu \mathrm{M}$ nontargeting oligonucleotides (NT siRNA), or control $(0 \mu \mathrm{M})$. After 4 days of treatment ( 7 days in culture), Strap mRNA was reduced by approximately $50 \%$ in the targeting vs the non-targeting groups and control groups; however, the difference was only significant between the targeting and non-targeting groups $(P<0.05 ;$ Supplementary Fig. 2). Based on image analysis, there was a reduction in the proportion of non-growing oocytes in fragments exposed to Strap siRNA relative to both control and NT siRNA $(P<0.001)$. This corresponded with an increase in the proportion of growing oocytes in those fragments exposed to Strap siRNA relative to controls and NT siRNA $(P<0.001)$ (Fig. 5A). The diameter of growing oocytes was also significantly increased relative to control $(P<0.05)$ and NT siRNA groups $(P<0.01)$ (Fig. 5B). The increase in oocyte size in fragments exposed to Strap siRNA was also associated with many Amh-positive granulosa cells (Fig. 5C).

\section{Effect of Strap supplementation on preantral follicle growth}

We then looked at the effect of exogenous STRAP on isolated growing follicles. Preantral follicles from d16 mice were cultured either in the absence (Control) or presence of $200 \mathrm{ng} / \mathrm{mL}$ rhSTRAP for $72 \mathrm{~h}$ (Fig. 6). Follicles exposed to rhSTRAP grew at a faster rate than controls; meaning treated follicles were significantly larger in diameter at $48 \mathrm{~h}(P<0.01)$ and $72 \mathrm{~h}(P<0.001)$ relative to untreated follicles (Fig. 6A). The morphological appearance of these cultured follicles was similar regardless of treatment group (Fig. 6B).

\section{Discussion}

In this study we show that STRAP, a TGFB pathwayregulating protein, is expressed in small follicles in the mouse ovary and is capable of influencing early follicle development. To examine the role of STRAP on follicle growth we used an in vitro system where pieces of neonatal (d4) mouse ovaries enriched with small, non-growing follicles were monitored in conditions that aimed to reduce or increase STRAP activity. In this context, inhibition of the protein by antibody neutralisation, or the transcript by RNA interference, caused a reduction in the proportion of non-growing follicles and a corresponding increase in the proportion of growing follicles. This shows the primary effect of STRAP inhibition is to promote the activation of nongrowing follicles. By comparison, when $\mathrm{d} 4$ ovaries were treated with exogenous STRAP protein, there was 

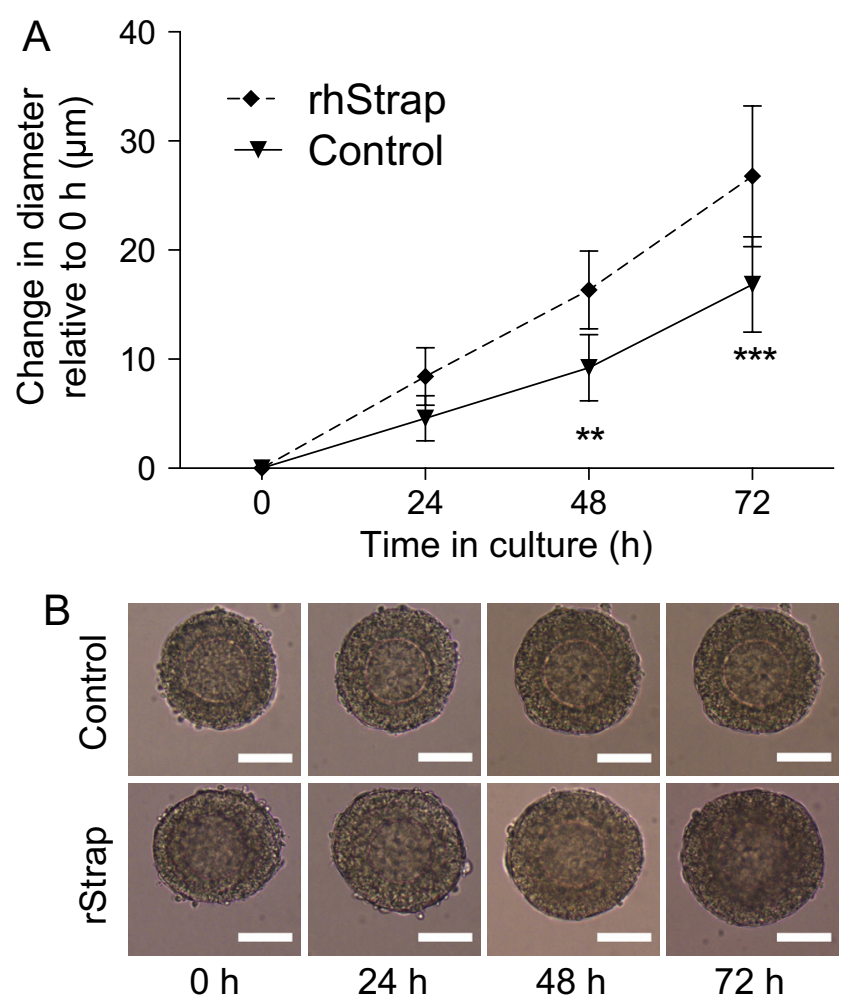

Figure 6 Effect of STRAP supplementation on preantral follicle growth in vitro. Preantral follicles were isolated from d16 mice and maintained under standard culture conditions (Control) or supplemented with $200 \mathrm{ng} / \mathrm{mL}$ recombinant human STRAP (rhSTRAP). 6-8 follicles were included per group for each ovary and diameters measured daily. Only morphologically healthy follicles were included in the analysis. Growth is plotted as the difference in diameter relative to $0 \mathrm{~h}$ and represents the mean $( \pm 95 \% \mathrm{Cl})$ of 7 ovaries $(n=7)$ at each time point (A). ${ }^{* *} P<0.01,{ }^{* * *} P<0.001$ vs control at the indicated time point. Bonferroni's multiple comparisons test. Examples of cultured preantral follicles are shown (B). Scale $=50 \mu \mathrm{m}$.

no effect on the proportion of non-growing follicles. Interestingly, STRAP protein seemed to promote the growth of follicles that had already begun to grow.

In other cell types, STRAP is known to act by stabilising a complex between TGFBR1 and SMAD7 to effectively inhibit downstream R-SMAD signalling (Datta \& Moses 2000) (Fig. 7A). We therefore looked at R-SMAD expression in relation to early follicle development. Initial results in this study confirmed previous observations that SMAD2/3 are found in GCs of small, single-layered follicles (Xu et al. 2002, Fenwick et al. 2013). SMAD2/3 protein expression is weak in growing follicles and similarly, the level of Smad3 mRNA is relatively reduced in d16 ovaries containing many more growing follicles than younger $\mathrm{d} 4$ ovaries. We also previously showed that SMAD $1 / 5 / 8$ protein is undetectable in small nongrowing follicles and is very clearly expressed in GCs of growing preantral follicles (Fenwick et al. 2013). This is consistent with levels of Smad1 and Smad5
mRNA, which are increased in $\mathrm{d} 16$ ovaries relative to $\mathrm{d} 4$. Together, the expression patterns of these R-SMADs suggest a stage-specific role for a sub-group of TGFB ligands and receptors, with those that activate the SMAD2/3 pathway as potentially key during the earliest stages. Since TGFBs often promote the expression of factors that negatively regulate SMAD signalling (Nakao et al. 1997, Stopa et al. 2000, Shi \& Massague 2003, Gao et al. 2013), we also looked at Smad7 and Strap in immature mouse ovaries. In this model, Smad7 and Strap transcript levels both followed a similar trend to Smad3, but not Smad1, Smad5 or Smad9 in d4-16 ovaries. In other cell types, SMAD7 can inhibit the Type 1 receptors upstream of both SMAD2/3 and SMAD1/5/9 (Hanyu et al. 2001, Kamiya et al. 2010). The suggestion from the expression data is that STRAP and SMAD7 may be associated with the SMAD2/3 pathway rather than SMAD1/5/9.

Using immunohistochemistry the STRAP protein appeared to localise to GCs of single and multi-layered preantral follicles consistent with a role for STRAP in modulating SMAD2/3 signalling. We did not see a reduction in STRAP protein in growing follicles in the same way that SMAD2/3 was reduced, although others have reported that the STRAP protein is highly stable (Reiner \& Datta 2011). The functional role of STRAP in follicle development and fertility has not been determined since knocking out the gene in mice causes embryonic lethality (Chen et al. 2004). Experimental reduction of STRAP in our culture model resulted in an increased proportion of follicles initiating growth. Thus, it is possible that a loss of STRAP permits increased SMAD2/3 signalling in GCs of small follicles. The role of SMAD2/3 signalling in small single-layered follicles is not clear, although mice lacking exon 8 of Smad3 have significantly more non-growing follicles and fewer growing follicles than wild-type mice at 3 months of age (Tomic et al. 2004). In human cultured human ovarian cortical tissues, treatment with a low concentration of activin inhibited follicle activation, while a higher concentration increased activation (Ding et al. 2010). Increased SMAD2/3 signalling may therefore be an important prerequisite for follicles to initiate growth.

In the same culture model we observed a positive influence of recombinant STRAP protein on growing follicles. Interestingly, there was no effect of exogenous STRAP on the small, non-growing follicles. The mechanism is not clear; however, the observed reduction in SMAD2/3 expression in follicles with multiple layers of granulosa cells provides some suggestion that loss of this signalling pathway may be important for growing follicles. A recent study in mice showed that inhibition of TGFBR1 in a similar ovary culture model resulted in accelerated oocyte growth and GC proliferation (Wang et al. 2014). Therefore, the differential actions of STRAP in small follicles may reflect the change in 

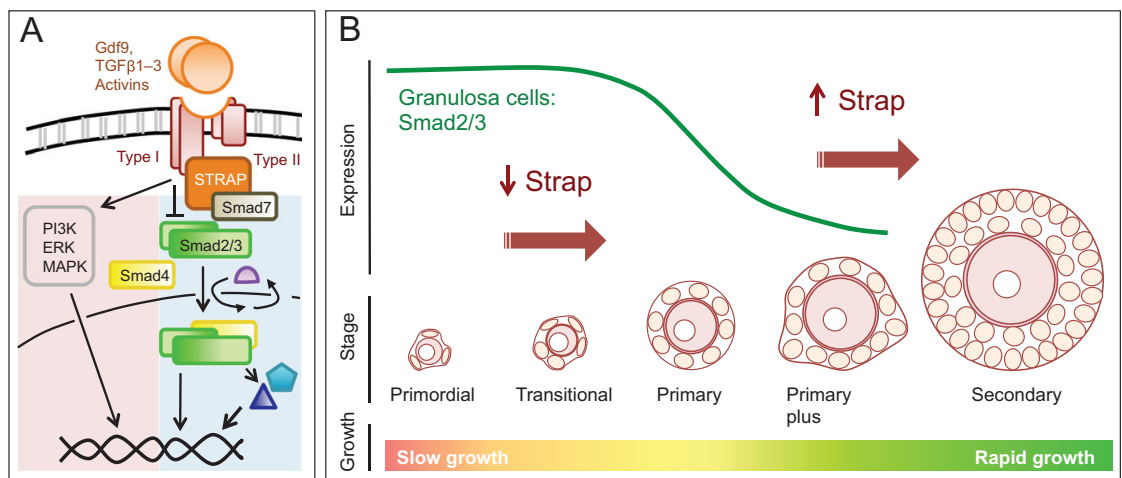

Figure 7 Regulation of the TGFB signalling pathway by STRAP in the context of early follicle development. (A) Canonical TGFB signalling involves ligands such as GDF9, TGFB1-3 or activins associating with Type I and II receptors, leading to recruitment and activation of R-SMADs (SMAD2/3) and SMAD4 complexes that enter the nucleus to regulate gene transcription in association with other co-factors (triangle, pentagon). STRAP inhibits the canonical pathway by forming a complex with the Type I receptor and SMAD7. STRAP can also interact with other pathways such as PI3K and MAPK to promote cell proliferation. (B) Granulosa cells of small single-layered follicles, which are relatively slow growing, express SMAD2/3. A reduction in STRAP may facilitate canonical TGFB signalling and promote the transition of growth through the early follicle stages. Further follicle growth is associated with a reduction in SMAD2/3, which may be facilitated by the ascribed role of STRAP in inhibiting TGFB signalling and driving TGFB-independent pathways associated with cell proliferation and follicle growth.

SMAD2/3 expression observed between non-growing and growing follicles.

STRAP also binds numerous proteins independent of the TGFB-SMAD pathway (Fig. 7A). For example, STRAP can interact with factors that promote proliferation (Seong et al. 2005, Kashikar et al. 2011, Reiner et al. 2011), regulate the epithelial/mesenchymal phenotype (Kashikar et al. 2010) and inhibit apoptosis (Jung et al. 2010). For these reasons, elevated levels of STRAP have been associated with tumourigenesis (Kim et al. 2007). Activation of the PI3 kinase/Akt pathway is known to promote early follicle development (Reddy et al. 2005, 2008, Liu et al. 2007, Adhikari \& Liu 2009). Within this pathway, STRAP is capable of binding PDK1, where it enhances phosphorylation of target substrates (Seong et al. 2005), including mTORC1, the activation of which is positively associated with early follicle development (Adhikari et al. 2010, Zhang et al. 2014). The observed increase in the proportion and size of growing follicles, as well as the increased rate of growth of isolated preantral follicles treated with recombinant STRAP protein may reflect these interactions with SMAD-independent pathways. Considering the stagedependent effects that we observed by either increasing or decreasing STRAP activity, we propose a model that explains how this factor may influence early follicle development, in accordance with the expression of TGFB-SMADs (Fig. 7B).

In this study we used a novel model of ovary culture to study the effects of STRAP in vitro. Cutting the ovary into fragments causes loss of the original architecture but still allows follicles to grow within a heterogeneous environment of other follicles and ovarian cells. A similar model has been used to evaluate the effects of chemotherapeutics on small follicles (Maiani et al. 2012). Culturing whole rodent ovaries has been carried out for some time (Eppig \& O’Brien 1996, O'Brien et al. 2003); however, the ability of this system to support follicles developing multiple layers of GCs is sometimes limited. In addition, the density of whole ovaries prohibits clear visualisation of individual follicles in vitro. In our cultures, we were able to observe oocytes during culture and also show that growing oocytes were associated with GC-specific Amh expression, an additional marker of follicle growth. Intriguingly, this model was amenable to various treatments including siRNA, as well as other macromolecules introduced to the culture media, such as recombinant protein and antibodies. The mechanism that allows the entry of these substances into the cells to interact with target proteins is not clear, but may involve non-specific receptor-independent endocytotic processes, such as clathrin-independent endocytosis or macropinocytosis (Maldonado-Baez et al. 2013, Mayor et al. 2014). Regardless of the mechanism involved, we observed clear dose-dependent effects of these macromolecules on oocyte growth in this system. These outcomes were evaluated in relation to controls, which indicates that the observed differences were specific to the macromolecule introduced to the system, and may therefore be an invaluable model for testing the effects of other exogenous compounds on early follicle development in vitro.

In summary we have shown that STRAP is expressed and is capable of influencing small follicle growth in the mouse ovary in vitro. The mechanism of action is not clear but the co-expression of SMADs during the early stages imply interactions with the TGFB pathway might be important, while the effect of STRAP on growing follicles could be via alternative signalling pathways. The subtle influences of proteins that interact with these pathways potentially lead to more substantial effects on 
the rate and number of follicles that develop to more advanced stages.

\section{Supplementary data}

This is linked to the online version of the paper at http://dx.doi. org/10.1530/REP-16-0612.

\section{Declaration of interest}

The authors declare that there is no conflict of interest that could be perceived as prejudicing the impartiality of the research reported.

\section{Funding}

This work was supported by a grant received from The Royal Society UK (RG130193) awarded to M A F and a scholarship from the HCED in Iraq awarded to I B S.

\section{References}

Adhikari D \& Liu K 2009 Molecular mechanisms underlying the activation of mammalian primordial follicles. Endocrine Reviews 30 438-464. (doi:10.1210/er.2008-0048)

Adhikari D, Zheng W, Shen Y, Gorre N, Hamalainen T, Cooney AJ, Huhtaniemi I, Lan ZJ \& Liu K 2010 Tsc/mTORC1 signaling in oocytes governs the quiescence and activation of primordial follicles. Human Molecular Genetics 19 397-410. (doi:10.1093/hmg/ddp483)

Chen WV, Delrow J, Corrin PD, Frazier JP \& Soriano P 2004 Identification and validation of PDGF transcriptional targets by microarray-coupled genetrap mutagenesis. Nature Genetics 36 304-312. (doi:10.1038/ng1306)

Da Silva-Buttkus P, Jayasooriya GS, Mora JM, Mobberley M, Ryder TA, Baithun M, Stark J, Franks S \& Hardy K 2008 Effect of cell shape and packing density on granulosa cell proliferation and formation of multiple layers during early follicle development in the ovary. Journal of Cell Science 121 3890-3900. (doi:10.1242/jcs.036400)

Datta PK \& Moses HL 2000 STRAP and Smad7 synergize in the inhibition of transforming growth factor beta signaling. Molecular and Cellular Biology 20 3157-3167. (doi:10.1128/MCB.20.9.3157-3167.2000)

Datta PK, Chytil A, Gorska AE \& Moses HL 1998 Identification of STRAP, a novel WD domain protein in transforming growth factor-beta signaling. Journal of Biological Chemistry 273 34671-34674. (doi:10.1074/ jbc.273.52.34671)

Datta PK, Blake MC \& Moses HL 2000 Regulation of plasminogen activator inhibitor-1 expression by transforming growth factor-beta -induced physical and functional interactions between smads and Sp1. Journal of Biological Chemistry 275 40014-40019. (doi:10.1074/jbc.C000508200)

Ding CC, Thong KJ, Krishna A \& Telfer EE 2010 Activin A inhibits activation of human primordial follicles in vitro. Journal of Assisted Reproduction and Genetics 27 141-147. (doi:10.1007/s10815-010-9395-6)

Dong J, Albertini DF, Nishimori K, Kumar TR, Lu N \& Matzuk MM 1996 Growth differentiation factor-9 is required during early ovarian folliculogenesis. Nature 383 531-535. (doi:10.1038/383531a0)

Edson MA, Nagaraja AK \& Matzuk MM 2009 The mammalian ovary from genesis to revelation. Endocrine Reviews 30 624-712. (doi:10.1210/ er.2009-0012)

Eppig JJ \& O'Brien MJ 1996 Development in vitro of mouse oocytes from primordial follicles. Biology of Reproduction 54 197-207. (doi:10.1095/ biolreprod54.1.197)

Fenwick MA, Mansour YT, Franks S \& Hardy K 2011 Identification and regulation of bone morphogenetic protein antagonists associated with preantral follicle development in the ovary. Endocrinology 152 3515-3526. (doi:10.1210/en.2011-0229)

Fenwick MA, Mora JM, Mansour YT, Baithun C, Franks S \& Hardy K 2013 Investigations of TGF-beta signaling in preantral follicles of female mice reveal differential roles for bone morphogenetic protein 15 . Endocrinology 154 3423-3436. (doi:10.1210/en.2012-2251)

Galloway SM, McNatty KP, Cambridge LM, Laitinen MP, Juengel JL, Jokiranta TS, McLaren RJ, Luiro K, Dodds KG, Montgomery GW et al. 2000 Mutations in an oocyte-derived growth factor gene (BMP15) cause increased ovulation rate and infertility in a dosage-sensitive manner. Nature Genetics 25 279-283. (doi:10.1038/77033)

Gao Y, Wen H, Wang C \& Li Q 2013 SMAD7 antagonizes key TGFbeta superfamily signaling in mouse granulosa cells in vitro. Reproduction 146 1-11. (doi:10.1530/REP-13-0093)

Gougeon A 1996 Regulation of ovarian follicular development in primates: facts and hypotheses. Endocrine Reviews 17 121-155. (doi:10.1210/ edrv-17-2-121)

Hanyu A, Ishidou Y, Ebisawa T, Shimanuki T, Imamura T \& Miyazono K 2001 The $N$ domain of Smad7 is essential for specific inhibition of transforming growth factor-beta signaling. Journal of Cell Biology 155 1017-1027. (doi:10.1083/jcb.200106023)

Hirshfield AN 1991 Development of follicles in the mammalian ovary. International Review of Cytology 124 43-101. (doi:10.1016/s00747696(08)61524-7)

Itoh S \& ten Dijke P 2007 Negative regulation of TGF-beta receptor/ Smad signal transduction. Current Opinion in Cell Biology 19 176-184. (doi:10.1016/j.ceb.2007.02.015)

Jung H, Seong HA, Manoharan R \& Ha H 2010 Serine-threonine kinase receptor-associated protein inhibits apoptosis signal-regulating kinase 1 function through direct interaction. Journal of Biological Chemistry 285 54-70. (doi:10.1074/jbc.M109.045229)

Kamiya Y, Miyazono K \& Miyazawa K 2010 Smad7 inhibits transforming growth factor-beta family type i receptors through two distinct modes of interaction. Journal of Biological Chemistry 285 30804-30813. (doi:10.1074/jbc.M110.166140)

Kashikar ND, Reiner J, Datta A \& Datta PK 2010 Serine threonine receptor-associated protein (STRAP) plays a role in the maintenance of mesenchymal morphology. Cellular Signalling 22 138-149. (doi:10.1016/j.cellsig.2009.09.024)

Kashikar ND, Zhang W, Massion PP, Gonzalez AL \& Datta PK 2011 Role of STRAP in regulating GSK3beta function and Notch3 stabilization. Cell Cycle 10 1639-1654. (doi:10.4161/cc.10.10.15630)

Kim CJ, Choi BJ, Song JH, Park YK, Cho YG, Nam SW, Yoo NJ, Lee JY \& Park WS 2007 Overexpression of serine-threonine receptor kinaseassociated protein in colorectal cancers. Pathology International $\mathbf{5 7}$ 178-182. (doi:10.1111/j.1440-1827.2007.02078.x)

Li Q, Pangas SA, Jorgez CJ, Graff JM, Weinstein M \& Matzuk MM 2008 Redundant roles of SMAD2 and SMAD3 in ovarian granulosa cells in vivo. Molecular and Cellular Biology 28 7001-7011. (doi:10.1128/ MCB.00732-08)

Liu L, Rajareddy S, Reddy P, Du C, Jagarlamudi K, Shen Y, Gunnarsson D, Selstam G, Boman K \& Liu K 2007 Infertility caused by retardation of follicular development in mice with oocyte-specific expression of Foxo3a. Development 134 199-209. (doi:10.1242/dev.02667)

Livak KJ \& Schmittgen TD 2001 Analysis of relative gene expression data using real-time quantitative PCR and the 2(-Delta Delta C(T)) Method. Methods 25 402-408. (doi:10.1006/meth.2001.1262)

Maiani E, Di Bartolomeo C, Klinger FG, Cannata SM, Bernardini S, Chateauvieux S, Mack F, Mattei M, De Felici M, Diederich M et al. 2012 Reply to: cisplatin-induced primordial follicle oocyte killing and loss of fertility are not prevented by imatinib. Nature Medicine 18 1172-1174. (doi:10.1038/nm.2852)

Maldonado-Baez L, Williamson C \& Donaldson JG 2013 Clathrinindependent endocytosis: a cargo-centric view. Experimental Cell Research 319 2759-2769. (doi:10.1016/j.yexcr.2013.08.008)

Massague J 2012 TGFbeta signalling in context. Nature Reviews Molecular Cell Biology 13 616-630. (doi:10.1038/nrm3434)

Mayor S, Parton RG \& Donaldson JG 2014 Clathrin-independent pathways of endocytosis. Cold Spring Harbor Perspectives in Biology 6 a016758. (doi:10.1101/cshperspect.a016758)

Middlebrook BS, Eldin K, Li X, Shivasankaran S \& Pangas SA 2009 Smad1-Smad5 ovarian conditional knockout mice develop a disease 
profile similar to the juvenile form of human granulosa cell tumors. Endocrinology 150 5208-5217. (doi:10.1210/en.2009-0644)

Nakao A, Afrakhte M, Moren A, Nakayama T, Christian JL, Heuchel R, Itoh S, Kawabata M, Heldin NE, Heldin CH et al. 1997 Identification of Smad7, a TGFbeta-inducible antagonist of TGF-beta signalling. Nature 389 631-635. (doi:10.1038/39369)

O'Brien MJ, Pendola JK \& Eppig JJ 2003 A revised protocol for in vitro development of mouse oocytes from primordial follicles dramatically improves their developmental competence. Biology of Reproduction $\mathbf{6 8}$ 1682-1686. (doi:10.1095/biolreprod.102.013029)

Pangas SA, Li X, Umans L, Zwijsen A, Huylebroeck D, Gutierrez C, Wang D, Martin JF, Jamin SP, Behringer RR et al. 2008 Conditional deletion of Smad1 and Smad5 in somatic cells of male and female gonads leads to metastatic tumor development in mice. Molecular and Cellular Biology 28 248-257. (doi:10.1128/MCB.01404-07)

Quezada M, Wang J, Hoang V \& McGee EA 2012 Smad7 is a transforming growth factor-beta-inducible mediator of apoptosis in granulosa cells. Fertility and Sterility 97 1452-1459, e1451-1456. (doi:10.1016/j. fertnstert.2012.03.024)

Reddy P, Shen L, Ren C, Boman K, Lundin E, Ottander U, Lindgren P, Liu YX, Sun QY \& Liu K 2005 Activation of Akt (PKB) and suppression of FKHRL1 in mouse and rat oocytes by stem cell factor during follicular activation and development. Developmental Biology 281 160-170. (doi:10.1016/j.ydbio.2005.02.013)

Reddy P, Liu L, Adhikari D, Jagarlamudi K, Rajareddy S, Shen Y, Du C, Tang W, Hamalainen T, Peng SL et al. 2008 Oocyte-specific deletion of Pten causes premature activation of the primordial follicle pool. Science 319 611-613. (doi:10.1126/science.1152257)

Reiner JE \& Datta PK 2011 TGF-beta-dependent and -independent roles of STRAP in cancer. Frontiers in Bioscience 16 105-115. (doi:10.2741/3678

Reiner J, Ye F, Kashikar ND \& Datta PK 2011 STRAP regulates c-Jun ubiquitin-mediated proteolysis and cellular proliferation. Biochemical and Biophysical Research Communications 407 372-377. (doi:10.1016/j. bbrc.2011.03.028)

Seong HA, Jung H, Choi HS, Kim KT \& Ha H 2005 Regulation of transforming growth factor-beta signaling and PDK1 kinase activity by physical interaction between PDK1 and serine-threonine kinase receptor-associated protein. Journal of Biological Chemistry 280 42897-42908. (doi:10.1074/jbc.M507539200)

Shi Y \& Massague J 2003 Mechanisms of TGF-beta signaling from cell membrane to the nucleus. Cell 113 685-700. (doi:10.1016/S00928674(03)00432-X)
Shimizu T, Kayamori T, Murayama C \& Miyamoto A 2012 Bone morphogenetic protein (BMP)-4 and BMP-7 suppress granulosa cell apoptosis via different pathways: BMP-4 via PI3K/PDK-1/Akt and BMP-7 via PI3K/PDK-1/PKC. Biochemical and Biophysical Research Communications 417 869-873. (doi:10.1016/j.bbrc.2011.12.064)

Stopa M, Anhuf D, Terstegen L, Gatsios P, Gressner AM \& Dooley S 2000 Participation of Smad2, Smad3, and Smad4 in transforming growth factor beta (TGF-beta)-induced activation of Smad7. THE TGF-beta response element of the promoter requires functional Smad binding element and E-box sequences for transcriptional regulation. Journal of Biological Chemistry 275 29308-29317. (doi:10.1074/jbc.M003282200)

Tomic D, Miller KP, Kenny HA, Woodruff TK, Hoyer P \& Flaws JA 2004 Ovarian follicle development requires Smad3. Molecular Endocrinology 18 2224-2240. (doi:10.1210/me.2003-0414)

Wakefield LM \& Hill CS 2013 Beyond TGFbeta: roles of other TGFbeta superfamily members in cancer. Nature Reviews Cancer 13 328-341. (doi:10.1038/nrc3500)

Wang ZP, Mu XY, Guo M, Wang YJ, Teng Z, Mao GP, Niu WB, Feng LZ, Zhao LH \& Xia GL 2014 Transforming growth factor-beta signaling participates in the maintenance of the primordial follicle pool in the mouse ovary. Journal of Biological Chemistry 289 8299-8311. (doi:10.1074/jbc.M113.532952)

Xu J, Oakley J \& McGee EA 2002 Stage-specific expression of Smad2 and Smad3 during folliculogenesis. Biology of Reproduction 66 1571-1578. (doi:10.1095/biolreprod66.6.1571)

Yan X, Liao H, Cheng M, Shi X, Lin X, Feng XH \& Chen YG 2016 Smad7 Protein Interacts with Receptor-regulated Smads (R-Smads) to Inhibit Transforming Growth Factor-beta (TGF-beta)/Smad Signaling. Journal of Biological Chemistry 291 382-392. (doi:10.1074/jbc.M115.694281)

Zhang H, Risal S, Gorre N, Busayavalasa K, Li X, Shen Y, Bosbach B, Brannstrom M \& Liu K 2014 Somatic cells initiate primordial follicle activation and govern the development of dormant oocytes in mice. Current Biology 24 2501-2508. (doi:10.1016/j.cub.2014.09.023)

Received 11 April 2016

First decision 13 May 2016

Revised manuscript received 14 November 2016

Accepted 22 November 2016 